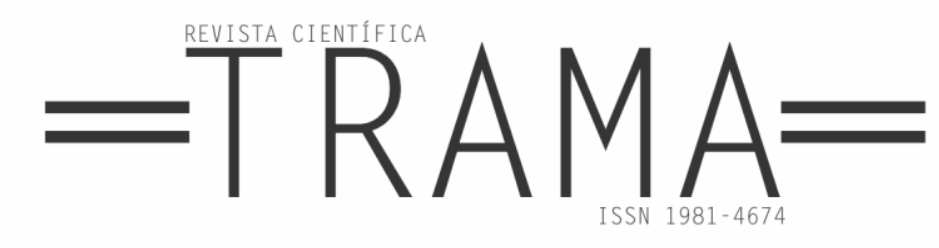

\title{
O CONFRONTO POLÍTICO-IDEOLÓGICO EM O GATO E A REVOLUÇÃO, DE ALCY CHEUICHE
}

\author{
Lucas da Cunha Zamberlan' \\ Deivis Jhones Garlet ${ }^{2}$
}

RESUMO: A novela O gato e a revolução, de Alcy Cheuiche, foi publicada em 1967 e, já no ano seguinte, depois de instituído o AI5, foi censurada e impedida de chegar aos leitores. Este trabalho pretende apresentar uma reflexão crítica sobre as funções sociais desempenhadas pelas diversas personagens na novela, destacando dois discursos notadamente perceptíveis no contexto de produção da obra e estetizados por meio dos enfrentamentos ideológicos apresentados nos diálogos da narrativa: a) o discurso comunista $e$ b) o discurso reacionário. Para lograrmos êxito na nossa pesquisa, utilizamos uma abordagem metodológica que principiou pela fortuna crítica acerca do conceito de ideologia proposto por Eagleton em Marxismo e crítica literária e com o aporte teórico que considerou o modelo de análise literária proposta por Antonio Candido, na obra Literatura e Sociedade.

PALAVRAS-CHAVE: O gato e a revolução; Alcy Cheuiche; ideologia; ditadura.

ABSTRACT: The novel O gato e a revolução, by Alcy Cheuiche, was published in 1967 and in the following year, after established AI5 was censored and prevented for readers. This article aims to present a critical discussion about the social functions performed by many characters in the novel, highlighting two speeches mainly kept in the context of work production and aestheticized through ideological confrontations contained presented in the dialogues of the narrative: a) communist discourse and b) reactionary discourse. To get success in our research, we use a methodological approach that began at the critical fortune about ideology concept proposed by Eagleton on Marxismo e crítica literária and with the theoretical framework that considered the literary analysis model proposed by Antonio Candido, on the book Literatura e Sociedade.

KEYWORDS: O gato e a revolução; Alcy Cheuiche; ideology; dictatorship.

\footnotetext{
${ }^{1}$ Docente substituto do Departamento de Letras Vernáculas da Universidade Federal de Santa Maria (UFMS) e doutorando do Programa de Pós-Graduação em Letras da mesma instituição.

${ }^{2}$ Doutor em Letras pela Universidade Federal de Santa Maria (UFSM). Docente em cursos Técnicos em Assuntos Educacionais na Universidade Federal de Santa Maria (UFMS), Cachoeira do Sul.
} 


\section{$=$ TRAMA $=$}

As ocasiões fazem as revoluções. (Machado de Assis - Esaú e Jacó)

\section{INTRODUÇÃO}

A novela intitulada $O$ gato e a revolução, obra de estreia do escritor gaúcho Alcy Cheuiche, foi publicada em 1967. No ano seguinte, depois de instituído o Ato Institucional número cinco, o livro acabou sendo censurado e, consequentemente impedido de chegar aos leitores por mais de vinte anos. No entanto, o fato não silenciou o escritor. De forma estratégica, Cheuiche escapou da mordaça imposta pela Ditadura ao propor no seu livro sequente - o romance de viés histórico denominado Sepé Tiaraju: romance dos sete povos das missões (1975) - um debate político-social extremamente pertinente ao contexto do regime de exceção em vigor por meio mascarado do distanciamento temporal, confirmando, assim, uma preocupação genuína com as causas urgentes da sua época.

Dessa forma, a literatura de Alcy Cheuiche, consagrada por romances de grande valor estético, como O mestiço de São Borja (1980), A Guerra dos Farrapos (1985), Ana sem terra (1990), Lord Baccarat (1993), A mulher do espelho (1996), Nos céus de Paris - Romance da vida de Santos Dumont (1998), Jabal Lubnan, as aventuras de um mascate libanês (2003), João Candido - o Almirante Negro (2010) e Farol da solidão (2015) e premiada com distinções importantes, dentre elas Ilha de Laytano, Prêmios RBS e Prêmio Laçador, consolida-se como um grande exemplo de literatura de matiz social desde a sua origem, entendendo esse tipo específico de literatura de acordo com a definição de Bittencourt,

compreende todos aqueles textos cuja ideia primordial é a análise da sociedade em suas macro e micro relações, abrangendo desde as que acontecem no interior da célula familiar, ou no contato entre patrão e empregado, até as grandes 


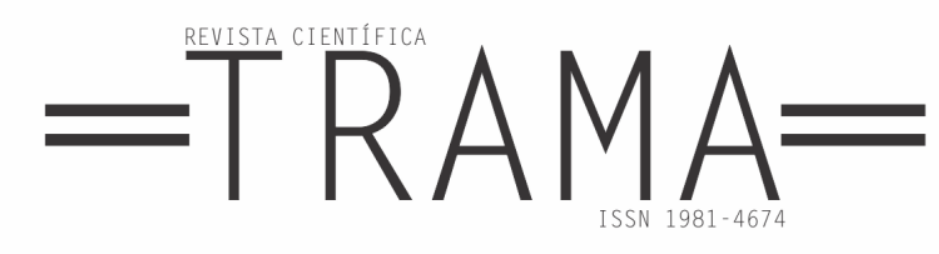

contradições do sistema capitalista, com as diferenças brutais entre os segmentos sociais, a perversa distribuição de renda, os valores / comportamentos dos setores privilegiados, os problemas do exercício do poder, da repressão, das liberdades individuais dos cidadãos, etc. (BITTENCOURT, 1999, p. 73-74).

Escrita durante o período de um ano em que o autor residiu na Alemanha, $O$ gato e a revolução capta a atmosfera político-ideológica da época ao configurar literariamente o contexto dos mais diferentes ambientes de Porto Alegre e seus habitantes, promovendo debates entre representantes de classes sociais distintas e descrevendo a efervescência do cenário estudantil daquele momento conturbado da história do Brasil. Conforme o próprio Cheuiche:

No capítulo passado no "Brahms", esquina da Garibaldi com Cristóvão Colombo, ouvi até o som do piano que musicava nossas discussões políticas. E vibrei com os argumentos de Antônio Carlos que admirava Marx mas não aceitava de cabeça baixa todos os seus dogmas. Se o comunismo tivesse permitido a liberdade religiosa, como prega em 1967 o jovem universitário, talvez nós estivéssemos vivendo hoje num mundo menos cruel (CHEUICHE, 1993, p.95).

Partindo dessa série de considerações iniciais, o presente artigo pretende apresentar uma reflexão crítica sobre as funções sociais desempenhadas pelas diversas personagens na novela, destacando dois discursos notadamente em voga no contexto de produção da obra e estetizados por meio do enfrentamento ideológico contido nos diálogos da narrativa: a) o discurso comunista e b) o discurso reacionário.

Para logramos êxito na nossa pesquisa, utilizamos uma abordagem metodológica que principiou pela fortuna crítica acerca do conceito de ideologia proposto por Eagleton em Marxismo e crítica literária (1976) e toma forma com o aporte teórico que considera o modelo de análise literária proposta por Antonio Candido, na obra Literatura e Sociedade (1980).

O enfrentamento político-ideológico é provocado, com segurança, pelas ideias contrastantes oriundas dos sujeitos pertencentes a classes sociais 


\section{$=\mathrm{TRAMA}=$}

distintas, ou seja, pelas ideologias reinantes, na acepção de Eagleton (1976) do termo,

A ideologia não é, em primeiro lugar, um conjunto de doutrinas; ela representa a maneira como os homens exercem os seus papéis na sociedade de classes, os valores, as ideias e as imagens que os amarram às suas funções sociais e assim evitam que conheçam a sociedade como um todo (EAGLETON, 2011, p. 36).

Cheuiche capta o confronto entre representantes dessas classes distintas, construindo, por meio dos recursos próprios da arte literária, da linguagem verbal, um painel sobre as tensões políticas do final da década de 1960. Considerando-se esse enfrentamento evidente na narrativa analisada, Antonio Candido, em Literatura e sociedade (1980), debate sobre os vínculos teóricos que podem se estabelecer entre a sociologia e a crítica literária. Variando entre diversas áreas do saber, o autor elenca seis modalidades de abordagem. A categoria de estudo mais apropriada, na sua concepção, entende que os elementos contextuais devem estar amalgamados à forma do texto, fazendo com que os fatos de uma determinada realidade se manifestem e se acomodem na configuração da obra de arte:

Neste caso, saímos dos aspectos periféricos da sociologia, ou da história sociologicamente orientada, para chegar a uma interpretação estética que assimilou a dimensão social como fator de arte. Quando isto se dá, ocorre o paradoxo assinalado inicialmente. O externo se torna interno e a crítica deixa de ser sociológica, para ser apenas crítica. O elemento social se torna um dos muitos que interferem na economia do livro, ao lado dos psicológicos, religiosos, linguísticos e outros. Neste nível de análise, em que a estrutura constitui o ponto de referência, as divisões pouco importam, pois tudo se transforma, para o crítico, em fermento orgânico de que resultou a diversidade coesa do todo (CÂNDIDO, 1980, p. 16).

Em outras palavras, Candido preconiza uma abordagem integralizada do objeto literário em análise, compreendendo-o como um produto cultural que apreende, na sua própria constituição, a complexa estrutura social a qual 


\section{$=$ TRAMA $=$}

este produto está inserido. Assim, é na minuciosa avaliação da transfiguração dos substratos externos (contexto) em internos (texto literário) que reside a crítica, disassociada da análise puramente sociológica.

Em $O$ Gato e a Revolução, o pano de fundo histórico (externo) remete ao contexto material da Guerra Fria, em uma totalidade global, e à Ditadura Civil-militar brasileira, em uma totalidade regional. De forma mais elucidativa, no âmbito mundial há a bipolarização entre o bloco capitalista, capitaneado pelos Estados Unidos da América (EUA), e o bloco comunista, tutelado pela União das Repúblicas Socialistas Soviéticas (URSS). Ignorar essa relação no que diz respeito à história brasileira, constituiria inadequação e aridez de análise. Portanto, a Ditadura Civil-militar (1964-1985) inscrevese neste cenário maior, podendo ser citado como exemplo a postura anticomunista dos militares no governo, com a instituição de discursos e ações orientadas pela Doutrina de Segurança Nacional, a qual explicitava dois nortes a serem seguidos: o combate aos subversivos, sobremodo os alcunhados de "comunistas" e o desenvolvimento do capitalismo associado e dependente do estrangeiro, conforme podemos ler em Comblin (1978). É neste contexto histórico, mundial e nacional, que podemos explicar - jamais justificar - a postura autoritária e violenta do governo militar, por meio de repressão policial, censura e tortura, por exemplo, afinal são ações apregoadas pela Doutrina de Segurança Nacional para combater o "perigo vermelho".

Também neste contexto, ocorrem as dissensões em relação aos militares, aos setores conservadores e ao capitalismo, como as manifestações estudantis, operárias, artísticas - literatura -, intelectuais até a luta armada na forma da guerrilha. Há, no Brasil dos anos 1960-1970, assim como no cenário mundial, mutatis mutandis, uma bipolarização de ideologias antagônicas: capitalismo versus socialismo (sem menosprezarmos 


\section{$=$ TRAMA $=$}

ideologias outras, mas que não constituem foco de nosso trabalho). A primeira enraízada nos setores conservadores, como governo militar, igreja e classe média; a segunda difundida entre operários, estudantes, intelectuais e artistas, ressalvando-se exceções para ambos os lados.

Assim, percebemos a história do período em conformidade com a acepção de Alves (1985) que salienta a tensão, o movimento dialético entre o Estado e a oposição. Na obra de Cheuiche, ocorre a incorporação estética deste contexto, como a própria Guerra do Vietnã, defendida pelos alinhados ao bloco capitalista e criticada pelos simpatizantes da ideologia comunista (e também por diversos movimentos contraculturais, como o movimento negro), de modo que a obra, podemos o afirmar, em sua singularidade estética, dialoga com o contexto de produção, com a história.

Esse cenário mundial, de natureza complexa, é estetizado de forma harmônica pelo autor. Sendo assim, o externo, observado por Candido, transforma-se em aspectos internos, por meio de uma série de características, como: a) a composição de capítulos aparentemente independentes que se encontram no final da narrativa, construindo partes que se unem na tentativa de evidenciar a totalidade pretendida pelo autor; b) a estrutura narrativa baseada no discurso direto, facilitando a exposição de ideias e o enfrentamento ideológico entre as personagens. Este recurso também empresta um dinamismo à narrativa, em harmonia com a própria estrutura de capitulos; c) e a criação de figuras ficcionais com posições políticas definidas, fazendo com que elas embasem suas argumentações e tentem, pelo debate, convencer seus oponentes políticos.

A fim de organizarmos metodologicamente a análise dos enfrentamentos explicitados na novela, fragmentamos o trabalho em partes, expondo as singularidades de cada embate, sempre com a preocupação 


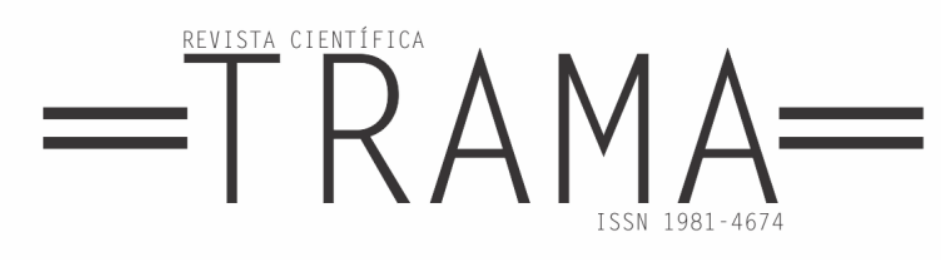

primeira de salientar os posicionamentos políticos-ideológicos das personagens e as internalizações no discurso literário.

\section{OS CONFRONTOS}

\section{Confronto I - O despertar: Eduardo Zimmermann X Estudantes}

Logo no início do capítulo II, na apresentação da personagem Eduardo Zimmermann, o leitor depara-se com uma discussão, no Bar Meia-Lua, entre o estudante de medicina descendente de alemães, vindo de Ijuí, com um grupo de colegas contrários ao seu posicionamento político. O debate em questão gira em torno da Guerra do Vietnam. Eduardo, em tom inflamado, defende os vietnamitas e questiona veementemente as intervenções dos estadunidenses no combate, aliando-se, dessa maneira, à ideologia comunista.

$\mathrm{O}$ enfrentamento ocorre de forma direta, formalizando-se por meio do discurso direto, com o narrador cedendo o espaço da narração às personagens, contudo, realizando ligeiras observações com o intuito de esclarecer o clima do momento:

- Se vocês admitem - continuou Eduardo - se vocês admitem que se matem covardemente...

- Covardemente não!

- Co-var-de-men-te! Se vocês admitem que se matem co-var-de-men-te homens, mulheres e crianças, só porque nasceram no Vietnam...

- E os americanos não morrem por acaso?

- Os que tem culpa não. Esses ficam na Wall Street fumando charuto. Mas isso é o outro lado da questão. Eu falava dos pobres infelizes que são bombardeados...

- Não amola, Eduardo! - retrucou um nanico gaiato - Isso é como a piada da velhinha: "guerra é guerra".

O grupo inteiro caiu na risada. Eduardo levantou-se e olhou como se os visse pela primeira vez.

- Boa noite.

- Mas o que é isso, Eduardo?!

- Deixa. Deixa que ele vai curtir o porre.

- Porre uma mer... - gaguejou o rapaz, avançando de punhos cerrados. 


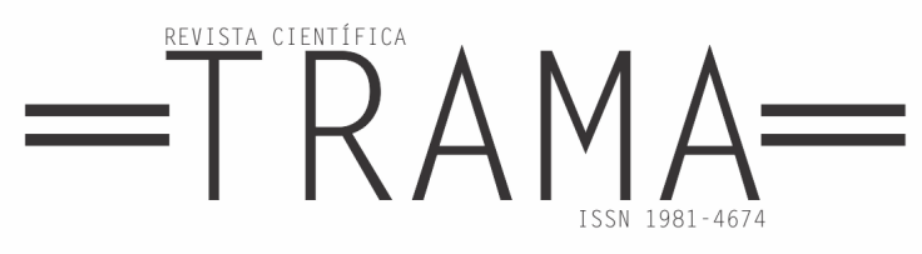

O Bar Meia-Lua acordou-se. Entrou a turma do "deixa-disso", com os argumentos costumeiros. Eduardo viu-se só no meio da noite gelada (CHEUICHE, 1993, p. 19).

O trecho revela-se de extrema relevância, pois relata não só a opinião de Eduardo acerca de um tema importante do contexto destacado e os argumentos costumeiros daqueles que defendiam a política ianque, mas também porque capta justamente o instante epifânico que o estudante se percebe notadamente diferente do grupo, não podendo mais compartilhar seu tempo e sua visão do mundo com os colegas que até então eram seus amigos e companheiros na capital. A partir desse momento do enredo, Eduardo buscará novas amizades, construídas, doravante, pelas afinidades ideológicas.

Além disso, um traço muito importante do diálogo chama a atenção. O tom sério e indignado de Eduardo e o contraste desse comportamento com as piadas e o descompromisso ideológico do grupo de estudantes. $\mathrm{O}$ assunto parece afetar o rapaz, ao contrário do que acontece com os seus oponentes. $\mathrm{O}$ desequilíbrio comportamental entre as partes apenas realça o efeito das diferenças entre os grupos. Com base nisso, o discurso comunista desvelase de forma engajada ao passo que o reacionário ocorre como um mero reflexo das opiniões da maioria da população. Estas últimas ideias refletem o encantamento dos brasileiros pelas oportunidades capitalistas, propagandeadas largamente na época e formalizado (internalizado, na acepção de Candido) na novela por meio do discurso da personagem Carlos Zimmermann, tio de Eduardo. Vizentini reflete sobre essa parte histórica importante do século XX:

As economias capitalistas apresentavam então um crescimento acelerado e contínuo, e o American way of life e a sociedade de consumo tornaram-se um padrão, um modelo a ser imitado, alcançado ou combatido. A expansão desse sistema lembrava o clima ufanista da belle époque que antecedeu à Primeira 


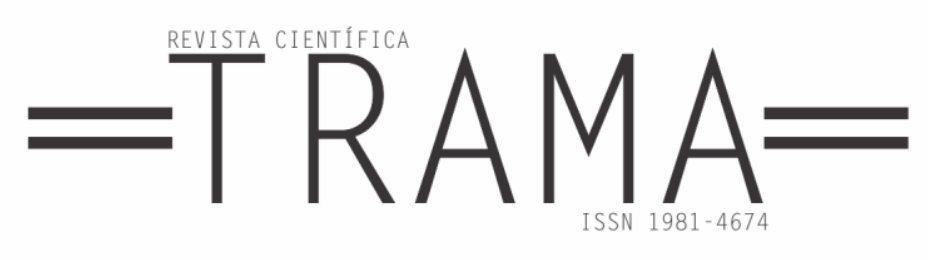

Guerra Mundial, um caminho linear e ascendente rumo a um futuro radioso para as sociedades ocidentais (VIZENTINI, 2004, p. 12).

Enfim, como realmente a personagem protagonista destacada passa por uma reformulação das suas ideias políticas, tornando-se um verdadeiro intelectual comunista, a sua apresentação aponta para a construção do "novo" Eduardo, prende o leitor na expectativa do percurso a ser traçado a partir desse fato e ainda explicita as opiniões de diferentes estudantes sobre o tema da Guerra do Vietnam, promovendo uma tensão que aumentará nos capítulos seguintes.

\section{Confronto II - A convicção: Eduardo Zimmermann X Carlos Zimmermann}

Esse enfrentamento é, na nossa leitura, o momento mais rico da novela, se considerarmos o debate de ideias opostas como modelo de análise. Eduardo, já inserido às concepções comunistas, depois de passar por um período de doutrinamento ideológico realizado pelo colega Antônio Carlos de Oliveira, filho de um taxista que não poupou esforços para o seu sucesso profissional, encontra-se com o seu tio.

Carlos F. Zimmermann, um advogado de grande sucesso e de reputação muito respeitada em Porto Alegre, sem dar explicações ao rapaz sobre motivo do encontro, faz uma longuíssima explanação política, dissertando sobre as duas potências mundiais, os Estados Unidos e a União Soviética. Eric Hobsbawm, em A era dos extremos: o breve século XX, reflete sobre essas duas superpotências:

A URSS controlava uma parte do globo, ou sobre ela exercia predominante influência - a zona ocupada pelo Exército Vermelho e/ou outras Forças Armadas comunistas no término da guerra - e não tentava ampliá-la com o uso de força 


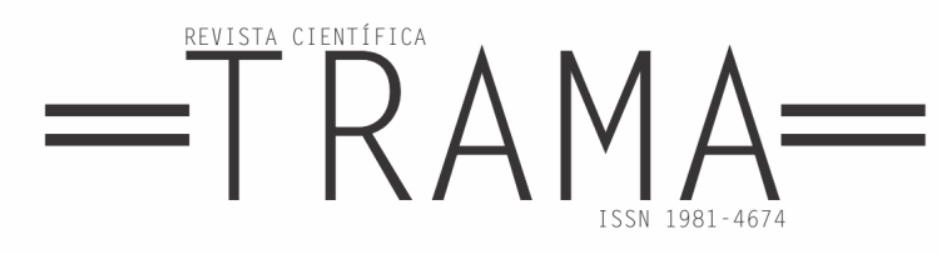

militar. Os EUA exerciam controle e predominância sobre o resto do mundo capitalista, além do hemisfério norte e oceanos, assumindo o que restava da velha hegemonia imperial das antigas potências coloniais. Em troca, não intervinha na zona aceita de hegemonia soviética (HOBSBAWM, 1995, p. 224).

Hobsbawm, no trecho, ao esclarecer, de maneira sumária, a dimensão das duas potências político-econômica vigente no período da Guerra Fria, acentua as distâncias ideológicas entre ambas, polarizando em versões diametralmente opostas, as escolhas políticas dos indivíduos circunscritos nesse contexto. Eduardo, como já foi abordado, dissocia-se dos seus colegas, movendo-se de uma posição a outra, desencadeando uma série de conflitos explorados nos capítulos sequentes, como nesta conversa tensa com o tio.

No discurso meticuloso de Carlos, a personagem preocupa-se primeiramente em expor todas as maravilhas proporcionadas pelo capitalismo americano e, no seu ponto de vista, as desigualdades oriundas do regime comunista:

- O mundo em que vivemos está dividido em dois hemisférios, perfeitamente distintos. De um lado, temos o comunismo marxista, ateu, cujo fracasso no plano econômico só pode ser comparado à gangrena de seu campo social. Os próprios soviéticos estão se convencendo disso e buscam, desesperadamente, uma volta às estruturas econômicas do lucro individual, realidade até bem pouco considerada obscena do outro lado da cortina de ferro. Os chineses se dilaceram entre si e fornecem armas aos países em vias de desenvolvimento, procurando com sua propaganda espúria o levante das massas analfabetas, em seu próprio proveito. No outro hemisfério, estamos nós e estão principalmente os Estados Unidos, esse maravilhoso país que tive oportunidade de conhecer e que é um verdadeiro exemplo de liberdade e democracia (CHEUICHE, 1993, p. 46-47, grifos nossos).

A superioridade social e familiar de Carlos perante o sobrinho não permite com que o estudante insufle-se contra o tio da mesma forma irada do incidente no Bar Meia-Lua. O oponente é diferente, e o respeito e consideração em relação à figura de Carlos, faz com que Eduardo faça apenas pequenas observações, como "Vide Vietnam" (CHEUICHE, 1993, p. 


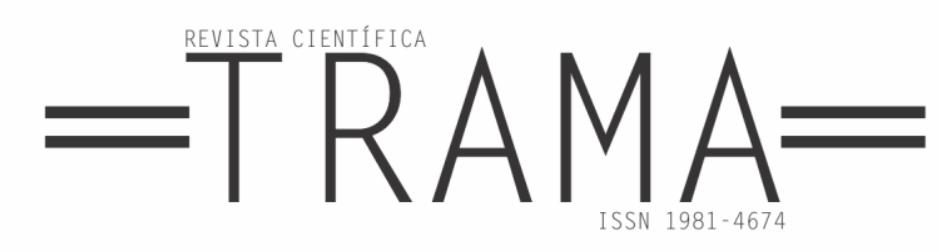

47) e "Parece-me que o Lyndon Johnson disse uma coisa parecida" (CHEUICHE, 1993, p.47). Mesmo no momento de maior argumentação, as palavras não apresentam a firmeza do enfrentamento anterior: “- Mas o senhor não pode negar, tio Carlos, que mais amoral ainda é ver indivíduos sem saber o que é uma fila de ônibus, uma favela, um filho que morre sem assistência médica... (CHEUICHE, 1993, p. 49).

Quando o sobrinho, já sem paciência, constata a inutilidade do diálogo, pergunta diretamente o motivo da conversa. Na sua concepção, havia uma certeza que nenhum argumento poderia mudar as concepções políticas de ambos, e perpetuar aquele embate, seria ameaçar uma ligação que, além de familiar, também era afetiva.

Carlos, então, mostra-se informado das relações de Eduardo com as personagens Lucie Maria Tamagnine, sua namorada, Marta Beatriz Tamagnine, sua cunhada e, principalmente, Antônio Carlos de Oliveira, namorado de Marta. Todos estes já estavam fichados pelo DOPS, o Departamento de Ordem Política e Social, que tinha o intuito de controlar e, por vezes, coibir os movimentos políticos e sociais contrários ao regime no poder. Entre o nome dos jovens, constava também o nome de Eduardo.

No entanto, a influência política de Carlos Zimmermann poderia fazer com que os papeis fossem destruídos a qualquer instante:

Eduardo levantara-se, a meio, na poltrona e contemplava o tio como uma criança que visse um mágico tirar um coelho da cartola.

- Quer dizer que eu...

- Quer dizer que o senhor está fichado, Dr. Eduardo. Fichadíssimo da Silva. Um amigo da DOPS, que me deve alguns favores, teve a gentileza de me trazer esses papéis, hoje pela manhã.

Carlos queria bem ao sobrinho e, consciente de ter ganho a batalha, voltou a pôr os papéis no cofre e sentou-se na poltrona frente a Eduardo.

- Vamos. Não precisas fazer essa cara de defunto. A tua ficha ainda não foi para o arquivo do DOPS e, se fores razoável, o assunto será encerrado hoje mesmo.

(CHEUICHE, 1993, p. 51). 


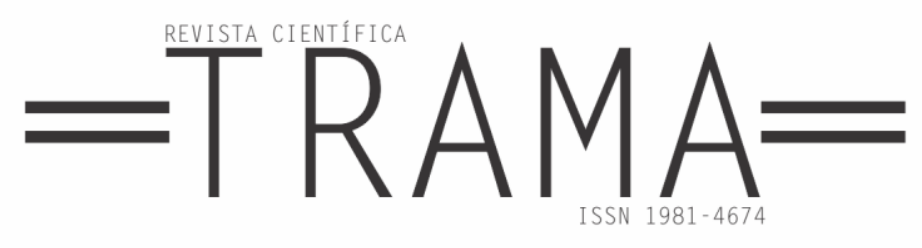

Em primeira instância, nota-se a corrupção do sistema pela possibilidade de se intervir no fichamento de indivíduos, cidadãos brasileiros, pela troca de favores. Além disso, o tom irônico empregado no discurso do advogado remete à ideia de profunda compreensão do sistema vigente e, inclusive, controle e possível intervenção nesse mesmo sistema. Ou seja, as condições de bem-estar social dos cidadãos brasileiros estavam mais afeitas aos que compartilhavam os ideais advindos dos Estados Unidos da América, em acordo com o que Hobsbawm havia observado no trecho anterior.

Então, perante a surpresa de Eduardo, Carlos pede para que o sobrinho se posicione, imaginando que ele, diante daquela realidade vermelha, pintada nas suas palavras pelo medo e a prisão, se afastasse dos seus amigos, da sua namorada e focasse seus esforços apenas na faculdade de Medicina, libertando-se das ideias comunistas e influências de Antônio Carlos,

Uma vez que teu tio abriu-te os olhos, nada mais tens do que escolher entre dois caminhos. No primeiro está tua família, teu país, a democracia, a liberdade (...) No outro caminho, está a agitação anarquista, o medo, a prisão e o ostracismo. Se continuares nesse trilho, dentro em pouco estarás tão atolado na lama comunista, que nem eu mesmo poderei te ajudar (CHEUICHE, 1993, p. 52).

Contudo, a despeito do que poderia se supor, o tio não convence o jovem Eduardo. Convicto de seu posicionamento, ele não o enfrenta novamente, mas faz sua escolha sem hesitações:

O rapaz levantou-se, despediu-se do tio, que sorria confiante, e saiu com a chave na mão, aparentando um ar preocupado.

Ao dobrar a primeira esquina, Eduardo deu um pinote, jogou a chave numa lata de lixo e desceu a lomba em direção ao bairro da Floresta, em passo semimarcial e assobiando a Marselhesa (CHEUICHE, 1993, p. 52).

Portanto, se ainda naquele primeiro enfrentamento, a transformação ideológica estava apenas começando a acontecer nas convicções de Eduardo, 


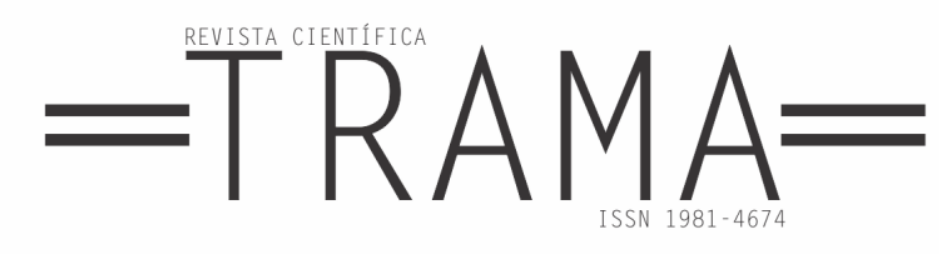

aqui, nesse segundo instante, o rapaz não titubeia e, embora não tenha demostrado um empenho para contrapor seu tio, demostra serenidade e amadurecimento, elementos construídos na certeza dos seus ideais políticos. Amadurecimento este conquistado principalmente nas discussões acaloradas com o seu mentor, Antônio Carlos.

\section{Confronto III - A Revolução: Antônio Carlos e Eduardo X Ciro}

A personagem Ciro aparece na narrativa no capítulo II, em um trecho em que ocorre uma imensa discussão sobre futebol. O amigo de Eduardo é colorado, ou seja, torcedor do Sport Clube Internacional, e enfrenta ferozmente alguns boêmios que defendiam o clube do Grêmio Football Porto-alegrense. A inserção do assunto não é por acaso, afinal o próprio narrador destina um papel político ao esporte e seus torcedores, descrevendo demoradamente as características dos times e as particularidades de cada um. Percebe-se, aqui, a mudança no estilo narrativo do autor, abrindo mão do discurso direto, sempre tão presente na obra, e a adoção de uma verve mais pedagógica, com a clara intenção de clarificar o pensamento do leitor.

Clubes de futebol não faltavam, mas a maioria dos torcedores gaúchos estava dividida em dois grupos em eterna rivalidade: os "gremistas", torcedores do Grêmio Football Portoalegrense, e o dos colorados do Sport Club Internacional. Abstraindo-se as inúmeras exceções, os comunas, em geral, eram colorados. Não só por analogia com as cores do Internacional, mas pelo fato de ele alcunhado de "clube do povo" adaptar-se como uma luva às tendências políticas do grupo. Um reacionário, embora houvesse aos milhares torcendo pelo Internacional, estava mais afeito a torcer pelo Grêmio, clube que, durante muitos anos, não permitia que os negros vestissem sua camiseta (CHEUICHE, 1993, p. 43-44).

A polarização da sociedade local, ou seja, porto-alegrense, em dois clubes rivais, um vermelho e outro azul, confunde-se, com certeza, com o pensamento político daquele contexto. Embora Ciro se posicione a favor do 


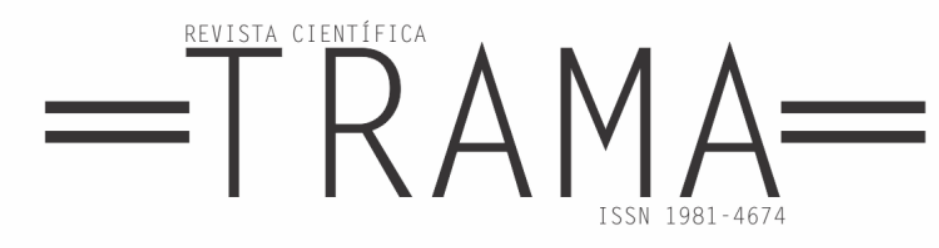

Internacional, ele não costumava defender seus ideais políticos com o mesmo empenho, apesar de simpatizar com o pensamento de Eduardo. Essa passagem, situada relativamente no início do livro acaba por preparar o leitor para o que se segue nos momentos finais da narrativa.

No capítulo VII, Eduardo e Ciro vão a um clássico do futebol gaúcho entre Grêmio e Internacional. Na saída, Antônio Carlos de Oliveira aproveita uma grande confusão gerada por uma das personagens centrais, o brigadiano Nondinho e tenta colocar em prática as suas ideias, e fazer a Revolução Brasileira Comunista:

- ... E, finalmente, chegou a nossa hora! Que cada homem válido cerre fileiras junto de nós! A tomada do Palácio Piratini será o nosso primeiro passo! Este carro está cheio de armas para os que quiserem estender a mão. Nada mais conseguirá deter a Revolução Brasileira! (CHEUICHE, 1993, p. 84).

Estás completamente louco - respondeu Ciro, agarrando Eduardo pelos dois braços - o que tu pensas que essa meia dúzia de gente desorganizada pode fazer contra um exército regular? Vai ser uma carnificina! (idem, p. 85).

Eduardo é tomado pela euforia oriunda da possibilidade de colocar realmente em prática tudo o que aguardava ansiosamente na companhia de Antônio Carlos, Marta e Lucie. Enquanto o jovem raciocina qual é a maneira mais adequada de auxiliar Antônio Carlos de forma prática, Ciro percebe rapidamente de que se trata de uma tentativa pífia, que jamais poderia tomar as proporções que os jovens idealistas imaginavam. E enfim, o enfrentamento ocorre, primeiramente com os argumentos de Ciro em resposta à decisão firme de Eduardo. Em confronto, a diferença é evidente:

- A Revolução está começada, companheiro! - disse ele, com voz emocionada. Nós dois vamos juntar gente e tomar a Rádio da Universidade. Ligeiro! Não há tempo a perder! - Nós?! Estás completamente louco - respondeu Ciro, agarrando Eduardo pelos dois braços - o que tu pensas que essa meia dúzia de gente desorganizada pode fazer contra um exército regular? Vai ser uma carnificina! (CHEUICHE, 1993, p. 85). 


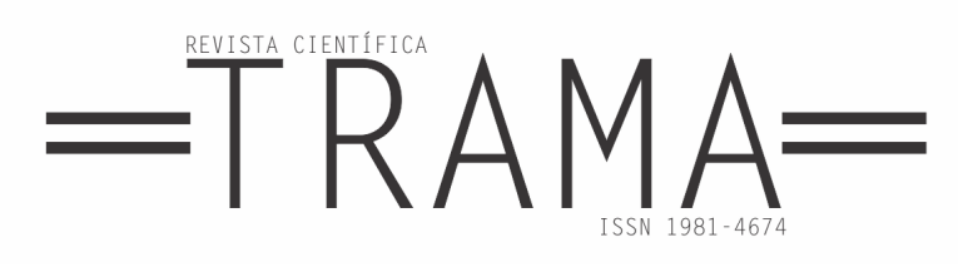

No que diz respeito a Ciro, toda a emotividade para debater os assuntos do futebol é substituída pela lucidez na constatação de que aquela revolução não teria êxito. É no contraste do comportamento do rapaz que Cheuiche expõe as contradições do ser humano, suas paixões e suas fraquezas.

Como resposta aos apelos de Ciro, Eduardo, entendendo a urgência da Revolução, apenas olha o amigo com desprezo e parte para a luta. Ciro, então, recorre para o enfrentamento físico, e, com três golpes, o coloca no chão e planeja a fuga de ambos para Quaraí. Ciro ainda desabafa: Quando conseguires chegares de volta a Porto Alegre, esta revolução de fim de linha já estará terminada. Como tem gente burra neste mundo, meu Deus! (CHEUICHE, 1993, p. 86).

A personagem Ciro, que, como se percebe, não era comunista, mas também não se enquadrava no grupo dos reacionários, consegue manter um distanciamento emotivo que o fez entender rapidamente o quão despreparada, improvisada e perigosa era aquela revolução. Além disso, sabendo que não convenceria Eduardo pelo enfrentamento discursivo, ele apela para a atitude extrema de levar o amigo para longe da capital. No final, ele estava certo. Os envolvidos foram presos e a tentativa subversiva foi contornada pelo governo.

Sendo assim, a partir dos elementos trabalhados nas três partes analisadas, bem como na introdução do presente trabalho, avaliamos a relevância da novela não só pelos traços artísticos intrínsecos ao arcabouço da obra, ou seja, pelos aspectos internos como afirma Candido, mas também como objeto estético que aprofunda questões fundamentais no esclarecimento de uma época marcada pela desvalorização da verdade e pela unilateralidade do debate político no Brasil. Afinal, como observa Auerbach (1972), um romance não é um produto desgarrado do tempo e do espaço, mas sim um considerável pedaço da história. 


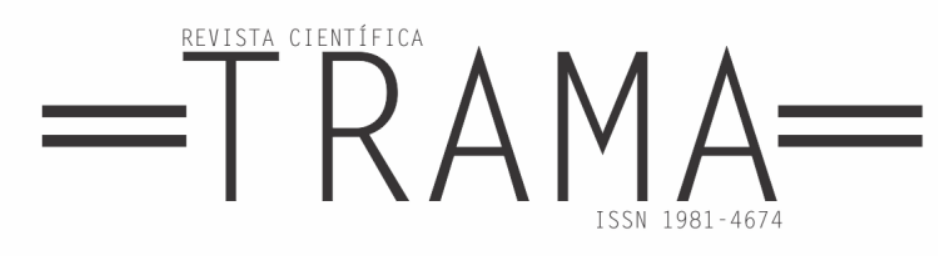

\section{REFERÊNCIAS}

ALVES, Maria Helena Moreira. Estado e Oposição no Brasil (1964-1984). 3 ed. Rio de Janeiro: Vozes, 1985.

AUERBACH, Erich. Introdução aos estudos literários. 2 ed. Tradução de José Paulo Paes. São Paulo: Cultrix, 1972.

BITTENCOURT, Gilda Neves da Silva. O conto sul-rio-grandense: tradição e modernidade. Porto Alegre: Editora UFRGS, 1999.

CANDIDO, Antonio. Literatura e sociedade. São Paulo: Editora Nacional, 1980.

CHEUICHE, Alcy. O gato e a revolução. Porto Alegre: Editora AGE, 1993.

COMBLIN, J. A Ideologia da Segurança Nacional: O Poder Militar na América Latina. Tradução de Veiga Filho. 2 ed. Rio de Janeiro: Civilização Brasileira, 1978.

EAGLETON, Terry. Marxismo e crítica literária. Tradução Matheus Corrêa. São Paulo: Unesp, 2011.

HOBSBAWM, Eric. A era dos extremos: o breve século XX. 1941-1991. São Paulo: Companhia das Letras, 1995.

VIZENTINI, Paulo Fagundes. A Guerra Fria: o desafio socialista à ordem americana. Porto Alegre: Leitura XXI, 2004. 